\title{
Foraging and Commuting Habitats of the Greater Horseshoe Bat, Revealed by High-Resolution GPS-Tracking
}

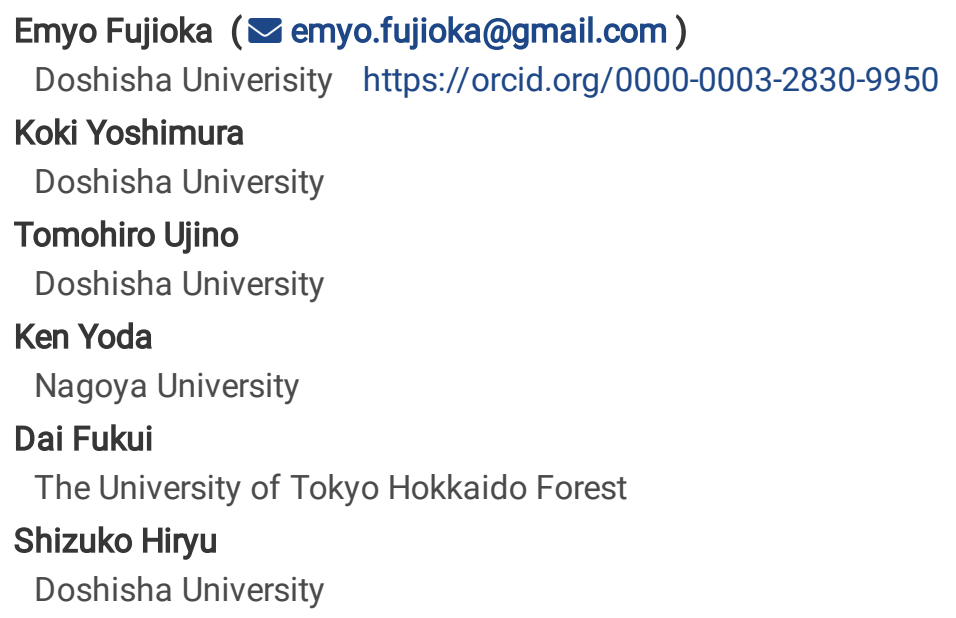

\section{Research}

Keywords: bio-sonar, Rhinolophus ferrumequinum nippon, animal movement, foraging, search pattern.

Posted Date: November 20th, 2020

DOI: https://doi.org/10.21203/rs.3.rs-80636/v1

License: (ㅇ (i) This work is licensed under a Creative Commons Attribution 4.0 International License. Read Full License 


\section{Abstract}

Background

Echolocating bats make a series of decisions to select their flight paths based on auditory information obtained by sonar as well as visual cues; accumulations of these flight routes are represented as daily movement patterns. However, there is still a lack of an understanding of continuous movements of echolocating bats in the wild (i.e., from meters to tens of kilometers). In this study, we investigated nightly flight paths of the Japanese greater horseshoe bat, Rhinolophus ferrumequinum nippon, using high-resolution GPS data loggers. Our aim was to identify foraging and commuting behavior based on the observed movement patterns and to investigate the relationship between these movement types and specific habitats.

\section{Results}

We found that the majority of tagged bats alternated between foraging and commuting behavior throughout the tracking period, and one individual moved $23.6 \mathrm{~km}$ from its roost. The bats usually left a foraging area in the opposite direction from which they entered it, indicating that almost all of the stay sites were on their way to another destination. The distance between two successive foraging sites was on average $332 \pm 398 \mathrm{~m}$ (mean \pm standard deviation), and half of all foraging periods lasted less than $3 \mathrm{~min}$. An analysis of habitat use revealed that the bats used conifer plantation and natural forests as pathways and feeding habitats.

\section{Conclusions}

Our findings suggest that the structure of the forests have a great influence on the nocturnal behavior of the greater horseshoe bats. Although this study has a descriptive character due to a relatively small number of tagged individuals, it was possible to elucidate the small-scale interactions between wild Rhinolophus bats and their environment using the latest high-resolution GPS technology, which will allow us to give new insights into the foraging ecology of echolocating bats in the wild.

\section{Background}

Animals choose a route towards a destination based on their innate sensing systems and behavioral strategies [1, 2]. Most bat species, except for some in the order Pteropodidae, are supposed to select their flight paths based mainly on information obtained by echolocation when light and other cues are not available [3]. Since their echolocation calls do not propagate usually over large distances in the air (<10 m [4]), most studies have focused on small-scale relationships between bat echolocation and flight routes in the laboratory and small-scale field experiments [5-9]. Recently, technological advances in the design of animal-borne devices have opened new avenues for research of bat navigation on a much larger spatial scale. Bio-logging (i.e. storing data within tags) has facilitated data collection of large-scale movement paths [10], and also accelerated the investigation of movement ecology of echolocating bats in the wild. The trajectory pattern of large-scale animal movement is investigated according to behavioral modes, i.e., intensive and extensive modes that show area-concentrated patterns in a relatively small-scale area and relocation patterns, respectively [11, 12]. For example, a GPS tracking study revealed that the flight patterns of Myotis bats are associated with the predictability of prey occurrence [13]; the mouse-eared gleaning bat, M. myotis, commutes to a particular foraging site with a predictable occurrence of prey in a straight line, whereas the Mexican fish-eating bat, $M$. vivesi, wanders over the ocean to search for ephemeral resources and exhibits intensive movement patterns in a local area while foraging. Although the navigational studies for echolocating bats have been conducted in small to large spatial scales, large-scale flight trajectories do not describe bat behavior in detail due to the long-time sampling intervals. As bats maneuver so adeptly that they could fly about several meters per second, more precise recording is needed.

The greater horseshoe bat (Rhinolophus ferrumequinum) is an appropriate model to investigate the relationship between the two flight modes, as it is known to forage in the fly-catcher style (i.e. bats hang on a tree branch to search for insect prey and then fly off to capture their prey) $[14,15]$. Therefore, the flight path of the bats is supposed to be shown in an area-concentrated pattern in a relatively small-scale during foraging, which consequently may result in two distinct flight patterns i.e., foraging (intensive) and commuting (extensive). Regarding movement ecology during natural foraging, many studies have been conducted in the greater horseshoe bat using radio-tracking [e.g., 16-21], and in recent years GPS-tracking [22]. According to these studies, the greater horseshoe bats preferred a particular habitat type during foraging (pasture, forest, riparian vegetation, etc.). In addition, they moved on average relatively short distances of a few kilometers during nightly foraging. However, the basic flight properties of the 
commuting and foraging behavior and how environmental features shape these movement patterns among flight modes still remain unknown because the accuracy and frequency of the positional measurements using radio-tracking and low-frequencysampling GPS-tracking [22] were not sufficient to identify the habitat type of the immediate surrounding of the bat during the flight. Knowledge of this property leads to a better understanding of the navigation strategies of echolocating bats from small to large spatial scales.

The purpose of this study is firstly to precisely distinguish between the commuting and foraging mode based on the flight paths during natural foraging. In a second step, we aim at describing the spatio-temporal characteristics of each flight mode. To address this purpose, we used high-resolution GPS positions (i.e. logging every 2-3 s) for the Japanese greater horseshoe bat (Rhinolophus ferrumequinum nippon) during nightly foraging. We hypothesized that the bats show alternating patterns of foraging and commuting, and navigate themselves to a habitat that is suitable for their fly-catcher foraging style. The investigation of the smallscale as well as the nocturnal movement behavior using high-resolution GPS-tracking will make it possible to support previous findings based on more concrete evidence and will contribute to dramatic progress in the understanding of the movement ecology of this bat species.

\section{Results}

\section{Overview}

We attached the high-resolution GPS data loggers to a total of 24 bats (see Methods for details), and collected data from a total of five loggers out of eight tagged bats that returned to the roost (i.e., three loggers were dropped elsewhere). In general, bats flew towards the northwest (Fig. 1A). Most bats with attached loggers left the roost (i.e. logging started) within about $1 \mathrm{~h}$ after sunset, which was similar to previously reported bat emergence times (Table 1) [15]. We observed foraging trajectory patterns (Fig. 1BC) among the flight paths of all bats. One of the five bats remained at a single location for over $4 \mathrm{~h}$ (bat $\mathrm{B}$ ); another flew away from a foraging area and returned repeatedly to that site (bat $A_{2}$, Fig. 1C) in a foray search pattern [23, 24]. Although bat $B$ was caught in a drizzling rain for approximately $1 \mathrm{~h}$ around 23:00, the weather was clear or cloudy during all other measurement periods (Japan Meteorological Agency, www.jma.go.jp). 
Table 1

Summary of bat flight data used in this study.

\begin{tabular}{|c|c|c|c|c|c|c|c|c|c|c|c|c|}
\hline Bat & Sex & $\begin{array}{l}\text { Logger } \\
\text { Type }\end{array}$ & $\begin{array}{l}\text { Logging } \\
\text { Interval } \\
\text { [s] }\end{array}$ & $\begin{array}{l}\text { Measured } \\
\text { Date }\end{array}$ & $\begin{array}{l}\text { Sunset* } \\
\text { Time }\end{array}$ & $\begin{array}{l}\text { Time } \\
\text { Log } \\
\text { Start }\end{array}$ & $\begin{array}{l}\text { Time } \\
\text { Log } \\
\text { End }\end{array}$ & $\begin{array}{l}\text { No. } \\
\text { Points }\end{array}$ & $\begin{array}{l}\text { Ratio } \\
\text { of } \\
\text { Stay }\end{array}$ & $\begin{array}{l}\text { No. } \\
\text { Stays }\end{array}$ & $\begin{array}{l}\text { Flight } \\
\text { speed** } \\
\text { (mean } \\
\pm \mathrm{SD} \\
{[\mathrm{m} / \mathrm{s}] \text { ) }}\end{array}$ & $\begin{array}{l}\text { Reason } \\
\text { of } \\
\text { Log } \\
\text { End }\end{array}$ \\
\hline$A_{1}$ & ] & $\begin{array}{l}\text { GiPSy- } \\
5\end{array}$ & 2 & $2015 / 9 / 4$ & 18:07 & $1: 37$ & $3: 50 * \star \star$ & 3536 & $28 \%$ & 3 & $\begin{array}{l}5.2 \pm \\
1.9(\mathrm{~N} \\
=2507)\end{array}$ & $\begin{array}{l}\text { Signal } \\
\text { lost }\end{array}$ \\
\hline$A_{2}$ & 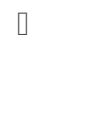 & $\begin{array}{l}\text { GiPSy- } \\
5\end{array}$ & 2 & $2015 / 9 / 5$ & 18:06 & $0: 17$ & $0: 34$ & 544 & $71 \%$ & 4 & $\begin{array}{l}4.2 \pm \\
2.1(\mathrm{~N} \\
=138)\end{array}$ & $\begin{array}{l}\text { Battery } \\
\text { out }\end{array}$ \\
\hline B & 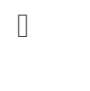 & $\begin{array}{l}\text { GiPSy- } \\
5\end{array}$ & 2 & $2015 / 9 / 3$ & 18:07 & 19:31 & $23: 45$ & 8002 & $100 \%$ & 1 & - & $\begin{array}{l}\text { Battery } \\
\text { out }\end{array}$ \\
\hline $\mathrm{C}$ & ] & $\begin{array}{l}\text { GiPSy- } \\
5\end{array}$ & 3 & 2016/6/10 & $19: 13$ & 19:32 & $23: 42$ & 5156 & $89 \%$ & 27 & $\begin{array}{l}3.8 \pm \\
1.5(\mathrm{~N} \\
=521)\end{array}$ & $\begin{array}{l}\text { Battery } \\
\text { out }\end{array}$ \\
\hline $\mathrm{D}$ & प & $\begin{array}{l}\text { GiPSy- } \\
5\end{array}$ & 3 & 2016/6/10 & 19:13 & 19:33 & $23: 29$ & 5298 & $72 \%$ & 42 & $\begin{array}{l}4.0 \pm \\
1.7(\mathrm{~N} \\
=1441)\end{array}$ & $\begin{array}{l}\text { Battery } \\
\text { out }\end{array}$ \\
\hline$E$ & ] & $\begin{array}{l}\text { GiPSy- } \\
5\end{array}$ & 3 & 2016/6/10 & 19:13 & $19: 49$ & $23: 00$ & 4101 & $80 \%$ & 17 & $\begin{array}{l}4.2 \pm \\
2.3(\mathrm{~N} \\
=803)\end{array}$ & $\begin{array}{l}\text { Battery } \\
\text { out }\end{array}$ \\
\hline \multicolumn{13}{|c|}{ * Data from National Astronomical Observatory of Japan were used. } \\
\hline \multicolumn{13}{|c|}{ ** Each flight speed was calculated using two consecutive positions in the commuting-mode trajectory (see Additional file 5) } \\
\hline & & & & & & & & & & & & \\
\hline
\end{tabular}

\section{Properties of each mode}

Using a clustering method that we proposed in the current study (refer to Methods for details), we identified and focused on the foraging and commuting modes, analyzing these in detail. For all of the tracked bats, except bat $A_{1}$, over $70 \%$ of the measured GPS positions of each bat were classified as foraging mode. Bat $A_{1}$ (male bat) flew relatively long distances interrupted by short stays ( $28 \%$ of all bat $A_{1}$ 's positions) and flew almost directly towards the northwest over a distance of $23.6 \mathrm{~km}$, which was the longest flight distance recorded in this study.

We also found that the bats repeatedly switched between foraging and commuting modes. They usually left a zone of foraging mode in the opposite direction from which they entered it (Fig. 2A), indicating that almost all of the stay sites were on their way to another destination. We recorded a maximum of 42 stays for a single bat (average: one 5-6-min stay; Table 1), which did not overlap between recorded flight trajectories. The majority of stationary periods lasted for less than two minutes, and half of all stays lasted less than three min (Fig. 2B). Most of the foraging-mode area were located close to each other with an average distance of $332 \pm 398 \mathrm{~m}$ (mean $\pm \mathrm{SD}, \mathrm{N}=87$ ) and a maximum travel distance of approximately $2.8 \mathrm{~km}$ and a negative exponential distribution (Fig. 2C).

\section{Habitat use}

We examined the habitat use of bats for foraging- and commuting-mode behavior by using land-use map data provided by the Ministry of Land, Infrastructure, Transport and Tourism (nlftp.mlit.go.jp). In this study, the habitats were categorized into the following six groups: natural forest, grassland, urban area, conifer plantation, water area and cropland (Fig. 3A). Note that, we examined the area in which the coordinates of the bats were located regardless of their position's proximity to the edge space. The urban area is widely distributed on the south side of the roost. The bats flew mainly toward natural forests. All of the habitats during the foraging-mode (white circles in Fig. 3A) were either natural forest (73.4\%) or conifer plantation (26.6\%) (Fig. 3B). Similarly, 
almost all habitats during the commuting-mode were also forested area $(75 \%$ and $22 \%$ for natural forest and conifer plantation respectively, Fig. $3 \mathrm{C}$ ). These results indicate that the main habitat where the bats used during foraging and commuting was forested area.

The GPS loggers used in this study recorded also data on the altitude, although not at high accuracy. Bat ground height during commuting mode was $16 \pm 20 \mathrm{~m}$ (mean $\pm S D, N=5456$ ), whereas the height of the stationary logger that we placed $1 \mathrm{~m}$ above the ground in the forest was $8 \pm 12 \mathrm{~m}$ (mean $\pm S D, N=985$ ), indicating that bat flight altitude was less than $10 \mathrm{~m}$ on average (i.e. ca. $9 \mathrm{~m}$ ). The forest canopy heights in the study area have been reported as approximately $15-20 \mathrm{~m}[25,26]$. These findings indicate that bats flew mainly within or under the forest canopy, not above it.

\section{Discussion}

Using bat flight trajectories recorded using GPS loggers, we classified intensive and extensive modes during nightly movement and quantified spatio-temporal features of these two navigational modes in R. f. nippon. Based on the foraging behavior of this species (fly-catcher style), these two modes are supposed to correspond to foraging and commuting, respectively. Strictly speaking, the intensive mode might include a resting mode. However, it is difficult to extract the resting mode from the positional data of the foraging bats even by using high-resolution GPS bio-logging due to their movement characteristics during perch-hunting (The details are presented below). As a result, we found that $R$. f. nippon alternated foraging within a time frame of a few minutes, which is quite similar to the Area Restricted Search (ARS) behavior observed in the movement patterns of animals such as some mammals, birds, and insects [27-29]. These characteristics of foraging and commuting behavior should be investigated considering sex differences in future studies. Although the sample size in the present study was small, we are confident that it will provide very valuable knowledge in order to advance the understanding of foraging ecology of this bat species in the wild.

\section{Habitat use}

In a previous study conducted in the UK using radio telemetry, $R$. ferrumequinum preferred to fly over pastures and in forests [20,30], whereas the bats in western Europe preferred residential areas and meadow orchards [21]. On the other hand, we found that the main habitat of our bats used in both of the foraging and commuting modes were forested areas, and the bats seemed to prefer flying within forest (see Fig. 3). Several factors may cause this habitat usage for the bats in our study area. First, forests are suitable for the flycatcher feeding style due to the abundance of tree branches. Second, Rhinolophus species generally have lower wing loading, which results in slow flight and good maneuverability [31]; flying within forests allows bats to avoid harsh weather conditions. Third, forests are a major source of flying insects, which are consumed by insectivorous bats. The landscape in this study was largely covered by forests than those in previous studies, and pastures, meadows, orchards (categorized into grassland in this study) and residential areas were rarely used by the bats. We need to consider that, depending on the interaction with the landscape, this bat species has such various habitat preferences.

In the forest, the bats often commuted along a forest road (Fig. 4), which was wide enough for cars to pass on one side (Additional file 1). Some previous studies using direct visual observation or infrared camera recordings also demonstrated that bats fly along fixed routes, so-called flyways, when commuting to foraging sites [32-34], such a route-following behavior is one of the various large-scale navigation strategies of bats [35]. Furthremore, the ultrasound detection range of bats is shorter than the ranges of visual sensory systems employed by other animals such as birds. The continuous echoes from the ground and from the left/right tree lines may be used as clues to help create a local space map for echolocating bats.

\section{Case study}

We recorded two cases of unrepeated commuting and foraging (bats $A_{1}$ and $B$ ). For bat $A_{1}$, the time of foraging mode during one trip was relatively short and flight speed was clearly higher compared to those of other trips, even by the same individual (see Table 1). Note that, bat $A_{1}$ might have flown at a higher ground speed than the others due to the wind effect: bat $A_{1}$ encountered approximately $2 \mathrm{~m} / \mathrm{s}$ wind from the south, bat $A_{2} 1 \mathrm{~m} / \mathrm{s}$ wind from the west and bats $C$, $D$, and E 3-4 m/s wind from the north (Japan Meteorological Agency, www.data.jma.go.jp). Compared to other trajectories, it seems that bat $A_{1}$ flew for purposes other than foraging, i.e., social behavior. Previous studies have reported that many insectivorous bat species, such as Myotis and Plecotus 
species, travel considerable distances and swarm at underground sites in late summer and autumn in temperate regions [36-38] for mating $[39,40]$ and/or to assess potential hibernation sites. Although there is no evidence of swarming behavior by Rhinolophus species so far, it is possible that bat $A_{1}$ has traveled a long distance because of an unknown social behavior during the mating season.

In contrast, bat B stayed continuously at a single site near the roost for over $4 \mathrm{~h}$ early in the night (Fig. 1C) (note that we visited this site and found that this was an area next to a pond, with a relatively low tree density). The positions of bat B had a Gaussian distribution in both the north-south and east-west directions (Additional file 2), with a greater variation along the north-south axis compared to the variation from our error-measurement when the logger was placed in a single location within the forest (Additional file 3, see Methods for details). This result suggests that these data were not the result of GPS logging error but rather a result of bat movements within the stay site near their roost. Note that, the bat's position located discretely by GPS during the foraging mode should not appear to move because the fly-catching greater horseshoe bats fly back to their perching positions before attacking their prey [15]. Therefore, it is thought to be difficult to discriminate foraging or resting from the foraging-mode trajectory data. In the case of bat $B$, the stay period was enormously longer than the other stays identified in this study. This bat might repeatedly change the hunting perches in the nearby area in the long-time foraging.

\section{Ethical considerations}

As bio-logging studies of wild echolocating bats have recently flourished, data quality is likely to be prioritized under a trade-off between logger size and battery life, resulting in the use of data logger weighted more than $10 \%$ of the body mass [41, 42]. In this study, we limited the logger weight to be relatively small, i.e., less than $10 \%$ of the bat's body mass, although the logger weight is recommended to be less than $3-5 \%$ of the body mass for the flying animals such as birds [43] and bats [44]. A previous study showed that no significant differences were observed between the behavior of echolocating bats $(M$. myotis and $M$. vivesi) carrying loggers with $15 \%$ of their body weight and non-tagged individuals [13]. The results of the present study showed that bats flew long distances at almost the same speed as reported by previous studies using radio telemetry $[45,46]$, suggesting that the influence of the data logger weight on bat flight performance was negligible. Nevertheless, the data logger needs to be smaller in the future in order to minimize the effect of the extra loading.

We also should consider how the stress caused by handling and logger attachment affects the bat's movement, as it might behave or move differently than usual and/or might lose body weight. The results showed that the time when the tagged bats emerged from their roost in the present study was almost the same as in a previous study [15]. In addition, the bodyweight of the attached bats when recapturing after a couple of days did not obviously decrease compared to the first capture (see Methods for details), which is consist of the range of the bodyweight fluctuation observed in this bat species on a daily basis among the reared individuals in our laboratory. These observations suggest that the extra loading due to the logger had little effect on the habitat use of the horseshoe bats. Furthermore, we recaptured a female that was investigated in the previous year during its pregnancy and we could not find any damages. In the present investigation, we caught and attached loggers to a total of 24 bats. We only recaptured 8 bats (33\% recapture rate) and succeeded in recovering the data from 5 individuals. In previous studies, the recapture rate of the greater horseshoe bats which were tagged with small metal rings (several few milli-meters) was around $40 \%[15,47]$. Therefore, the low recapture rate in this study is unlikely due to the extra loading from the GPS data logger alone. However, at present, the effect of logger attachment on the recovery rate of individuals as well as local populations has not been quantitatively assessed. Therefore, detailed investigations of the effects of logger attachment on the bats' behavior and health are needed.

\section{Conclusion}

We used high-resolution GPS bio-logging data and a flight mode classification method to determine that (i) greater horseshoe bats remained within a stay area repeatedly, to a maximum of about 10 times per hour during large-scale nightly navigation, and (ii) bats mainly commute and forage in natural forests or conifer plantations, and commuted locally and reliably along a forest road. Our findings suggest that the forests and their structures have a great influence on the nocturnal behavior of the greater horseshoe bats. The results of this fine-scale bio-logging study will support our understanding of the navigation and acoustical sensing strategies of insectivorous echolocating bats in the wild.

\section{Methods}




\section{Bats and study site}

The target species of this study was Rhinolophus ferrumequinum nippon, which has a body length and mass of approximately 6$8 \mathrm{~cm}$ and 20-30 g, respectively [48]. R. f. nippon starts to forage shortly after sunset and hunts flying insects mainly in a flycatcher style $[14,15]$. We caught the bats using butterfly nets at their day roost, an abandoned pillbox in Tomakomai, southern Hokkaido, Japan (N 42 $\left.41^{\prime} 00.2^{\prime \prime} \mathrm{E} 141^{\circ} 40^{\prime} 13.1^{\prime \prime}\right)$, during the daytime on a total of 7 days: June 2 and September 3, 2015; June 10, 11, and 12, 2016; and September 2 and 5, 2016. We then shaved dorsal hair of each bat outside the roost and attached loggers using Skin Bond (Osto-bond, Montreal Ostomy Inc., Canada). A forest and a golf course are located north of the roost, and an urban area lies to its south. The forests are mainly natural secondary forest dominated by Quercus crispula with interspersed patches of conifer (Larix kaempferi) plantations. Body mass was measured with an electronic scale (Handy-mini-1476, TANITA, Tokyo). All bats were tagged with numbered aluminum rings ( $4.2 \mathrm{~mm}$, Lambournes Ltd., Leominster, England) that were attached to their forearms.

\section{GPS tracking}

The GPS data logger that we used in this study was GiPSy-5 (Technosmart, Italy; $2.3 \mathrm{~g}$ ), which is capable of logging position in highresolution. The GiPSy-5 s were set to log every two or three seconds, for continuous logging over a period of approximately $4 \mathrm{~h}$, to measure high-resolution smooth flight paths. Timers were set to start logging at 19:00 o'clock. The data-loggers were set to sleep for $15 \mathrm{~min}$ if they failed to detect satellite signals for $5 \mathrm{~min}$. The weight of the attached logger was less than $10 \%$ of that of the bat and exceeded the $5 \%$ threshold of body mass commonly recommended for bats [44]. However, recent GPS studies have confirmed that bats may be able to cope with additional loads exceeding $10 \%$ of their body mass without apparent changes to foraging behavior or body mass [41, 42]. In this study, flight speeds (ground speed) of the bats were calculated to be similar to or greater than previously reported values $[45,46]$, suggesting that the influence of data logger weight on bat flight performance was negligible. The attached loggers were collected by recapture the day after attachment at the same roost. We used a remover liquid (Uni-Solve Adhesive Remover, Smith and Nephew, UK) to remove the data loggers as gently as possible from the backs of the bats. There were no distinct changes in body weight between deployment and recovery (-1 g for three bats in 2016, no data in 2015). In addition, the dorsal fur of several recaptured individuals that were tracked in the previous year fully grew back.

\section{Data analysis}

When R. f. nippon flies in forests, GPS measurement error may be relatively high. Therefore, we measured the position error of GiPSy-5 data loggers at three different sites in the forest near the roost, prior to data analysis. The measured positional error followed a Gaussian distribution, with a peak at the center of the coordinates and a standard deviation (SD) $\sigma$ of 7-8 $\mathrm{m}$ in the north-south and east-west direction (Additional file 3). In previous studies, first-passage time analysis and state-space analysis have been proposed for the extraction of local search paths $[12,49]$. In the current study, due to the GPS positional error and the hunting strategy of R.f. nippon, their local search path during perch hunting appears difficult to detect by these traditional clustering methods even with high-resolution measurements. Thus, we reconstructed a simple method to properly extract the intensive mode behavior (i.e., foraging mode) based on the time window and positional variation in GPS tracking data. We classified each GPS point as belonging either to the foraging or commuting behaviors, including the positional error, as follows: we assigned foragingmode behavior to any position with a maximum distance (max- $d_{\text {window }}$ ) of $<50 \mathrm{~m}$ (about $\pm 3 \sigma$ ) between two points logged within a particular time window $t_{\text {window }}$ of the current position. A longer $t_{\text {window }}$ reduces the error detection of foraging mode but does not extract short foraging bout, and a shorter $t_{\text {window }}$ does the opposite. $t_{\text {window }}$ should be shorter in order to accurately extract the short foraging bout. However, if $t_{\text {window }}$ is set inappropriately, as short as 10 or $20 \mathrm{~s}$, max- $d_{\text {window }}$ may not exceed $50 \mathrm{~m}$ even in the commuting mode due to the low flight speed and the GPS positional error. Furthermore, since the observed flight speed of $R$. $f$. nippon is greater than 3-4 m/s in the laboratory [50], movement of less than $50 \mathrm{~m}$ in 30 seconds (i.e., $1.7 \mathrm{~m} / \mathrm{s}$ on average) is considered as stay mode, not commuting. Therefore, we set $t_{\text {window }}$ to $30 \mathrm{~s}$ for the current study. When max- $d_{\text {window }}$ exceeded $50 \mathrm{~m}$ during $30 \mathrm{~s}$, the position would be assigned to the commuting-mode behavior. To minimize false classifications due to positional error, we used smooth processing ("smooth" function with 5-point moving average algorithm in the Matlab R2016b environment; Mathworks, USA) for the max- $d_{\text {window }}$ time series. In rare cases, e.g. when the logger was stationary, max- $d_{\text {window }}$ exceeded $50 \mathrm{~m}$ during a time window of $30 \mathrm{~s}$, so that a given GPS-point was classified as belonging to the commuting mode. To correct this false classification, we reclassified any GPS-point classified as "commuting mode" to "foraging mode" when it was preceded and followed by a "foraging mode" position within an area of $50 \mathrm{~m} \times 50 \mathrm{~m}$. An example of the result of this procedure is provided in the Supplemental information (Additional file 4). The flight speed and turning angle obtained from the extracted position data of each 
mode showed a clear distribution with a single peak. Note that, the turning angle in the foraging mode is close to a uniform distribution because it is mainly due to an error. This method avoids overestimating the time spent on the foraging-mode behavior of the bats (Additional file 5). We performed this analysis using a custom-made program in Matlab. The geographical information system analysis was performed using the ArcGIS Desktop 10.4 software (Esri Japan Corporation).

\section{Abbreviations}

GPS

Global positioning system,

\section{Declarations}

Ethics approval and consent to participate: Experiments were performed with permission from the Hokkaido Regional Environment Office, Ministry of the Environment Government of Japan. (2015; 21-27-0077 - 21-27-0092: 2016; 21-28-0088 - 21-28-0093).

Consent for publication: Not applicable

Availability of data and materials: The datasets generated and analyzed during the current study are available in the Movebank Data Repository, https://doi.org/10.5441/001/1.nd3hk754 (Fujioka et al., 2020).

Competing interests: The authors declare no conflict of interest.

Funding: Our research was supported by a Grant-in-Aid for Young Scientists (B) (Grant No. JP15K18078 and JP19K16237), Scientific Research (A) (Grant No. JP18H03786 and JP16H01769) and Scientific Research on Innovative Areas (Grant No. JP16H06542) from the Japan Society for the Promotion of Science (JSPS).

Author contributions: EF and SH designed the study; EF, K. Yoshimura, TU, and DF performed the experiments; EF, KY, KY, and DF analyzed the data; EF, K. Yoda, DF, and SH wrote the paper. All authors gave final approval for publication.

Acknowledgments: For the assistance during the fieldwork, thanks to: Takuya Nishioka, Kazuya Motoi, Masaru Kondo, Taito Banda, Kan Sato, Fumiya Hamai, and Caitlin Campbell. We thank Olga Heim for her help in improving the manuscript.

\section{References}

1. Bartumeus F, Da Luz MGE, Viswanathan GM, Catalan J. Animal Search Strategies: A quantitative random-walk analysis. Ecology. 2005;86(11):3078-87.

2. Nathan R, Getz WM, Revilla E, Holyoak M, Kadmon R, Saltz D, Smouse PE. A movement ecology paradigm for unifying organismal movement research. Proc Natl Acad Sci USA. 2008;105(49):19052-9.

3. Griffin DR. Listening in the dark: the acoustic orientation of bats and men. New Haven: Yale University Press; 1958.

4. Schnitzler H-U, Moss CF, Denzinger A. From spatial orientation to food acquisition in echolocating bats. Trends Ecol Evol. 2003;18:386-94.

5. Ghose K, Moss CF. Steering by hearing: a bat's acoustic gaze is linked to its flight motor output by a delayed, adaptive linear law. J Neurosci. 2006;26(6):1704-10.

6. Chiu C, Xian W, Moss CF. Flying in silence: Echolocating bats cease vocalizing to avoid sonar jamming. Proc Natl Acad Sci USA. 2008;105(35):13116-21.

7. Kounitsky P, Rydell J, Amichai E, Boonman A, Eitan O, Weiss AJ, Yovel Y. Bats adjust their mouth gape to zoom their biosonar field of view. Proc Natl Acad Sci USA. 2015;112(21):6724-9.

8. Fujioka E, Aihara I, Sumiya M, Aihara K, Hiryu S. Echolocating bats use future-target information for optimal foraging. Proc Natl Acad Sci USA. 2016;113(17):4848-52.

9. Sumiya M, Fujioka E, Motoi K, Kondo M, Hiryu S. Coordinated Control of Acoustical Field of View and Flight in ThreeDimensional Space for Consecutive Capture by Echolocating Bats during Natural Foraging. PLoS ONE. 2017;12(1):e0169995. 
10. Rutz C, Hays GC. New frontiers in biologging science. Biol Lett. 2009;5:289-92.

11. Kölzsch A, Alzate A, Bartumeus F, de Jager M, Weerman EJ, Hengeveld GM, Naguib M, Nolet BA, van de Koppel J. Experimental evidence for inherent Lévy search behaviour in foraging animals. Proc. R. Soc. B 2015;282: 20150424.

12. Schick RS, Loarie SR, Colchero F, Best BD, Boustany A, Conde DA, et al. Understanding movement data and movement processes: current and emerging directions. Ecol Lett. 2008;11(12):1338-50.

13. Egert-Berg K, Hurme ER, Greif S, Goldstein A, Harten L, Herrera Montalvo LG, et al. Resource Ephemerality Drives Social Foraging in Bats. Curr Biol. 2018;28(22):3667-73.

14. Schnitzler H-U, Hackbarth $\mathrm{H}$, Heilmann U, Herbert H. Echolocation behavior of rufous horseshoe bats hunting for insects in the flycatcher-style. J Comp Physiol A. 1985;157(1):39-46.

15. Funakoshi K, Maeda F. Foraging activity and night-roost usage in the Japanese greater horseshoe bat, Rhinolophus ferrumequinum nippon. Mammal study. 2003;28(1):1-10.

16. Stebbings RE. Radio tracking greater horseshoe bats with preliminary observations on flight patterns. Symp Zool Soc Lond. 1982;49:161-73.

17. Duvergé PL, Jones G. Greater horseshoe bats-activity, foraging behaviour and habitat use. British Wildlife. 1994;6:69-77.

18. Bontadina F. Conservation ecology in the horseshoe bats Rhinolophus ferrumequinum and Rhinolophus hipposideros. Dissertation, Zoological Institute, University Bern; 2002.

19. Billington G. Radio tracking study of greater horseshoe bats at Chudleigh Caves and Woods Site of Special Scientific Interest. English Nature Research Reports. 2003;496:1-36.

20. Flanders J, Jones G. Roost use, ranging behavior, and diet of greater horseshoe bats (Rhinolophus ferrumequinum) using a transitional roost. J Mamm. 2009;90(4):888-96.

21. Dietz M, Pir JB, Hillen J. Does the survival of greater horseshoe bats and Geoffroy's bats in Western Europe depend on traditional cultural landscapes? Biodivers Conserv. 2013;22(13-14):3007-25.

22. Jeon YS, Kim SC, Han SH, Chung CU. Characteristics of the Home Range and Habitat Use of the Greater Horseshoe Bat (Rhinolophus ferrumequinum) in an Urban Landscape. J Env Sci Int. 2018;27(8):665-75.

23. Conradt L, Bodsworth EJ, Roper TJ, Thomas CD. Non-random dispersal in the butterfly Maniola jurtina: implications for metapopulation models. Proc R Soc Lond B. 2000;267:1505-10.

24. Conradt L, Zollner PA, Roper TJ, Frank K, Thomas CD. Foray Search: An Effective Systematic Dispersal Strategy in Fragmented Landscapes. Am Nat. 2003;161(6):905-15.

25. Ishii HT, Tanabe S, Hiura T. Exploring the relationships among canopy structure, stand productivity, and biodiversity of temperate forest ecosystems. Forest Science. 2004;50(3):342-55.

26. Hayashi M, Saigusa N, Oguma H, Yamagata Y. Forest canopy height estimation using ICESat/GLAS data and error factor analysis in Hokkaido, Japan. ISPRS Journal of Photogrammetry Remote Sensing. 2013;81:12-8.

27. Nakamuta K. Switchover in searching behavior of Coccinella septempunctata L.(Coleoptera: Coccinellidae) caused by prey consumption. Appl Entomol Zool. 1982;17(4):501-6.

28. Benedix JH Jr. Area-restricted search by the plains pocket gopher (Geomys bursarius) in tallgrass prairie habitat. Behav Ecol. 1993;4(4):318-24.

29. Weimerskirch H, Pinaud D, Pawlowski F, Bost C-A. Does prey capture induce area-restricted search? A fine-scale study using GPS in a marine predator, the wandering albatross. Am Nat. 2007;170(5):734-43.

30. Duvergé PL, Jones G. Use of farmland habitats by greater horseshoe bats. In: Tattersall F, Manley W, editors. Conservation \& Conflict, Westbury Publishing. 2003:pp. 64-81.

31. Norberg UM, Rayner JMV. Ecological morphology and flight in bats (Mammalia; Chiroptera): wing adaptations, flight performance, foraging strategy and echolocation. Phil Trans R Soc Lond B. 1987;316(1179):335-427.

32. Krull D, Schumm A, Metzner W, Neuweiler G. Foraging areas and foraging behavior in the notch-eared bat, Myotis emarginatus (Vespertilionidae). Behav Ecol Sociobiol. 1991;28(4):247-53.

33. Limpens HJGA, Kapteyn K. Bats, their behaviour and linear landscape elements. Myotis. 1991;29(6):39-47. 
34. Schaub A, Schnitzler H-U. Flight and echolocation behavior of three vespertilionid bat species while commuting on flyways. J Comp Physiol A. 2007;193:1185-94.

35. Yovel Y, Ulanovsky N. Bat Navigation. In: Byrne JH, editor. Learning and Memory: A Comprehensive Reference. Second Edition: Academic Press; 2017. pp. 333-45.

36. Parsons KN, Jones G, Davidson-Watts I, Greenaway F. Swarming of bats at underground sites in Britain-implications for conservation. Biol Conserv. 2003;111(1):63-70.

37. Rivers NM, Butlin RK, Altringham JD. Autumn swarming behaviour of Natterer's bats in the UK: population size, catchment area and dispersal. Biol Conserv. 2006;127(2):215-26.

38. Furmankiewicz J, Duma K, Manias K, Borowiec M. Reproductive status and vocalisation in swarming bats indicate a mating function of swarming and an extended mating period in Plecotus auritus. Acta chiropterologica. 2013;15(2):371-85.

39. Kerth G, Kiefer A, Trappmann C, Weishaar M. High gene diversity at swarming sites suggest hot spots for gene flow in the endangered Bechstein's bat. Conserv Genet. 2003;4(4):491-9.

40. Furmankiewicz J, Altringham J. Genetic structure in a swarming brown long-eared bat (Plecotus auritus) population: evidence for mating at swarming sites. Conserv Genet. 2007;8(4):913-23.

41. Cvikel N, Egert-Berg K, Levin E, Hurme E, Borissov I, Boonman A, et al. Bats Aggregate to Improve Prey Search but Might Be Impaired when Their Density Becomes Too High. Curr Biol. 2015;25:206-11.

42. Roeleke M, Blohm T, Kramer-Schadt S, Yovel Y, Voigt CC. Habitat use of bats in relation to wind turbines revealed by GPS tracking. Sci Rep. 2016;6:28961.

43. Phillips RA, Xavier JC, Croxall JP. Effects of satellite transmitters on albatrosses and petrels. Auk. 2003;120(4):1082-90.

44. Aldridge HDJN, Brigham RM. Load carrying and maneuverability in an insectivorous bat: a test of the $5 \%$ "rule" of radiotelemetry. J Mamm. 1988;69(2):379-82.

45. Aldridge $\mathrm{H}$. Kinematics and aerodynamics of the greater horseshoe bat, Rhinolophus ferrumequinum, in horizontal flight at various flight speeds. JãuExp Biol. 1986;126(1):479-97.

46. Tian B, Schnitzler H-U. Echolocation signals of the greater horseshoe bat (Rhinolophus ferrumequinum) in transfer flight and during landing. J Acoust Soc Am. 1997;101(4):2347-64.

47. Dietz C, Dietz I, Ivanova T, Siemers BM. Seasonal and regional scale movements of horseshoe bats (Rhinolophus, Chiroptera: Rhinolophidae) in northern Bulgaria. Nyctalus (N F). 2009;14(1-2):52-64.

48. Matsuta N, Hiryu S, Fujioka E, Yamada Y, Riquimaroux H, Watanabe Y. Adaptive beam-width control of echolocation sounds by CF-FM bats, Rhinolophus ferrumequinum nippon, during prey-capture flight. J Exp Biol. 2013;216:1210-8.

49. Fauchald $P$, Tveraa $T$. Using first-passage time in the analysis of area-restricted search and habitat selection. Ecology. 2003;84(2):282-8.

50. Hiryu S, Shiori Y, Hosokawa T, Riquimaroux H, Watanabe Y. On-board telemetry of emitted sounds from free-flying bats: compensation for velocity and distance stabilizes echo frequency and amplitude. J Comp Physiol A. 2008;194:841-51.

\section{Figures}



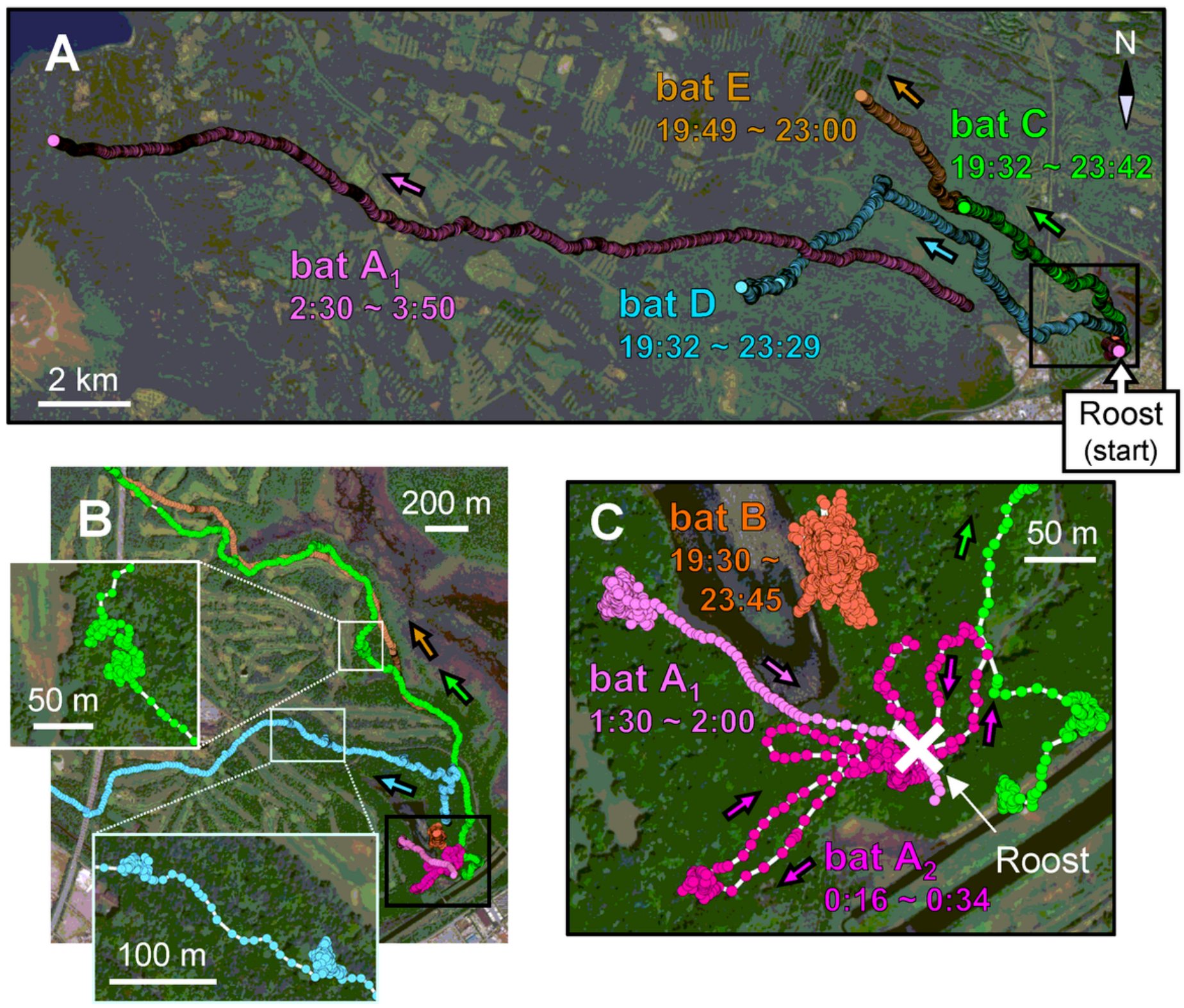

Figure 1

(A-C) Flight trajectories measured by the GPS tracking of the bats drawn on large- (A), medium- (B), and small-scale (C) satellite images. Arrows represent bat flight directions. The time in the figure indicates the local time. Note: The designations employed and the presentation of the material on this map do not imply the expression of any opinion whatsoever on the part of Research Square concerning the legal status of any country, territory, city or area or of its authorities, or concerning the delimitation of its frontiers or boundaries. This map has been provided by the authors. 

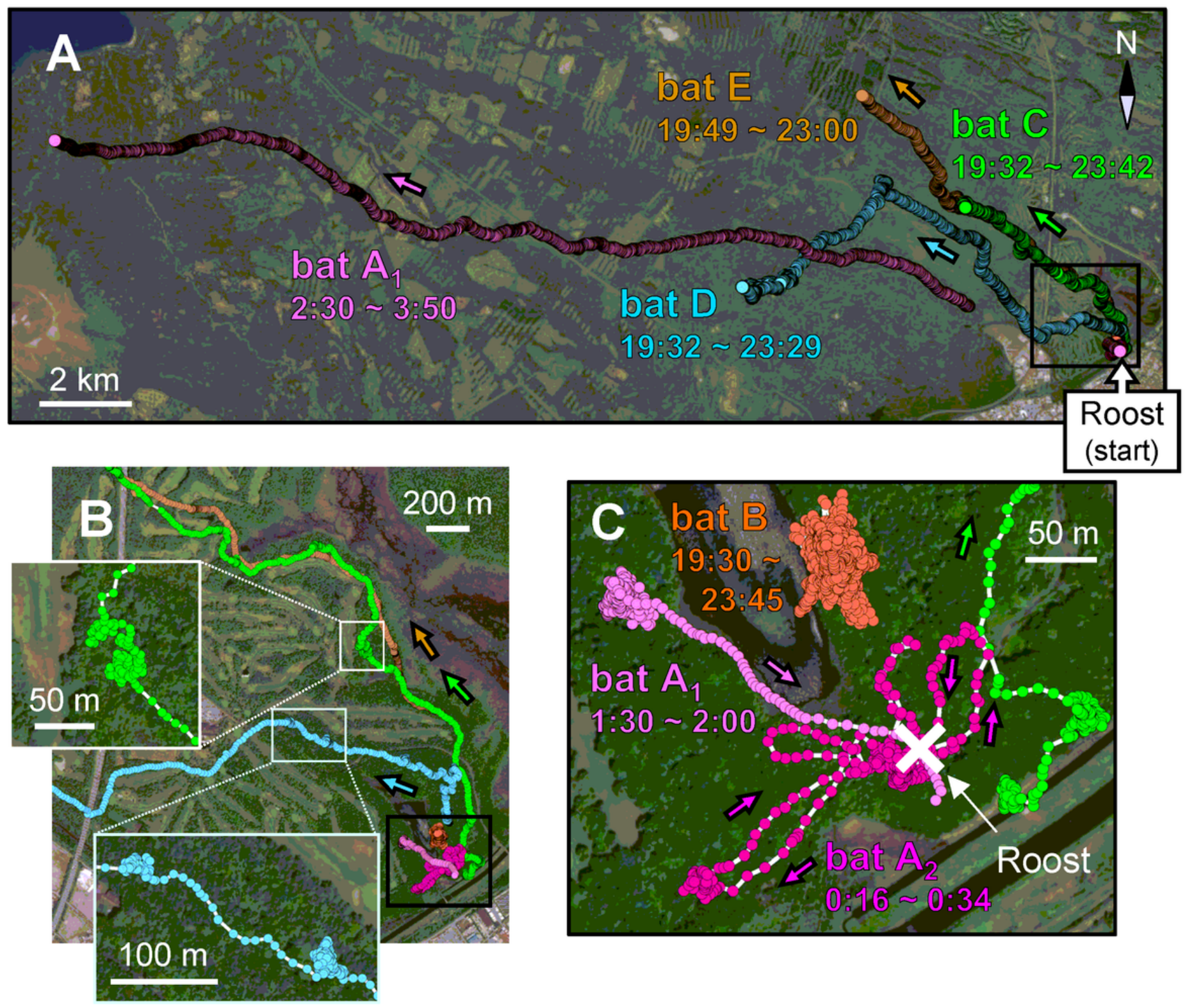

Figure 1

(A-C) Flight trajectories measured by the GPS tracking of the bats drawn on large- (A), medium- (B), and small-scale (C) satellite images. Arrows represent bat flight directions. The time in the figure indicates the local time. Note: The designations employed and the presentation of the material on this map do not imply the expression of any opinion whatsoever on the part of Research Square concerning the legal status of any country, territory, city or area or of its authorities, or concerning the delimitation of its frontiers or boundaries. This map has been provided by the authors. 

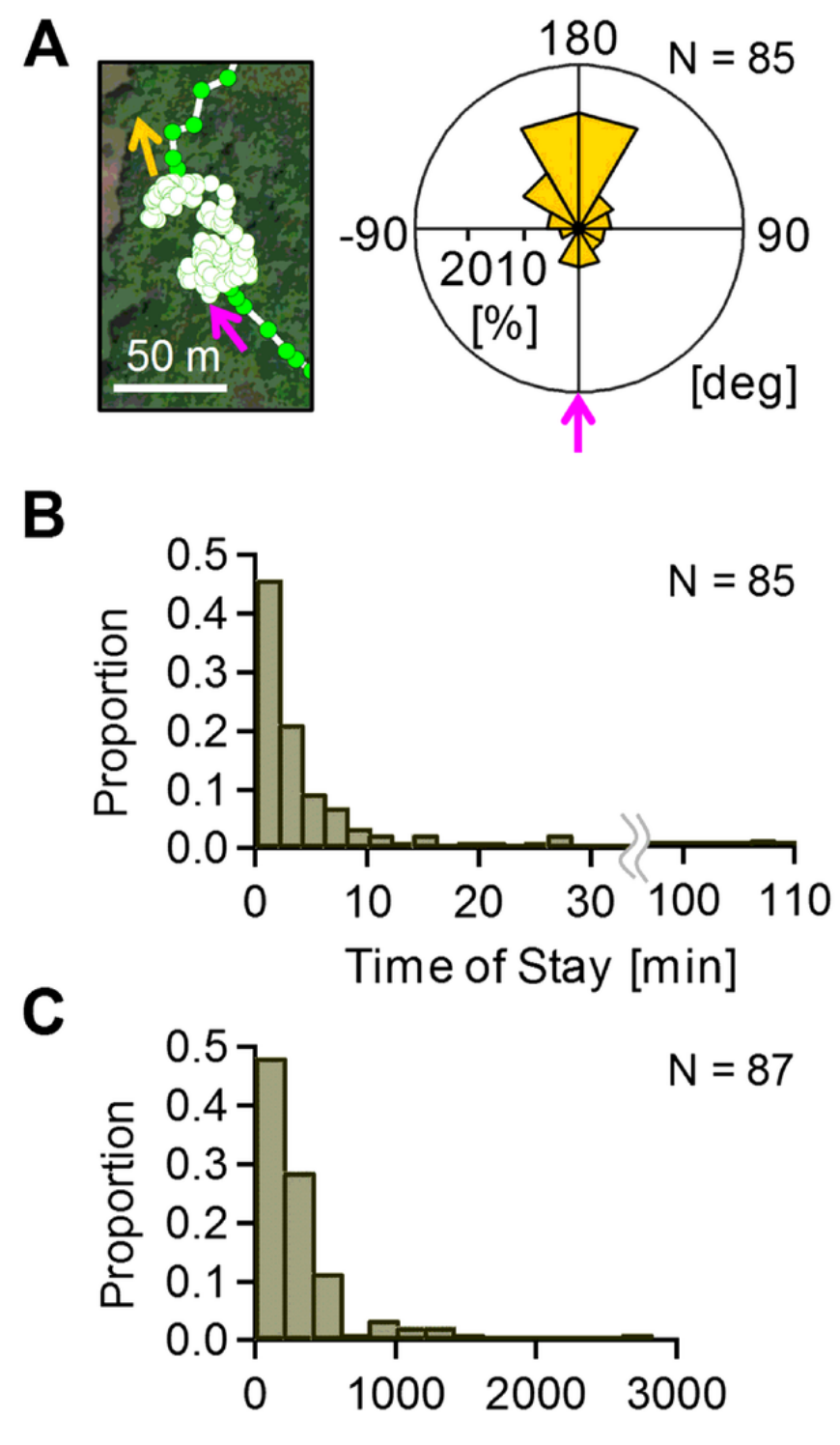

\section{Distance between Stay [m]}

Figure 2

(A) (Left) Example of trajectory pattern around the foraging mode (open circles). Magenta and yellow arrow indicates direction in which bats aimed to fly immediately before entering and after leaving the site of foraging mode, respectively. (Right) Distribution of directions in which bats left the site of foraging mode relative to the direction of entry (magenta direction). (B) Proportional distribution of time bats spent at the site of foraging mode. If the start point of the trajectories of each bat was categorized as foraging-mode, the time of the first stay was not used (the same is true for the last stay). (C) Proportional distribution of distances between two successive stay sites. A geodesic line was used to calculate distances. Note: The designations employed and the presentation of the material on this map do not imply the expression of any opinion whatsoever on the part of Research Square concerning the legal status of any country, territory, city or area or of its authorities, or concerning the delimitation of its frontiers or boundaries. This map has been provided by the authors. 

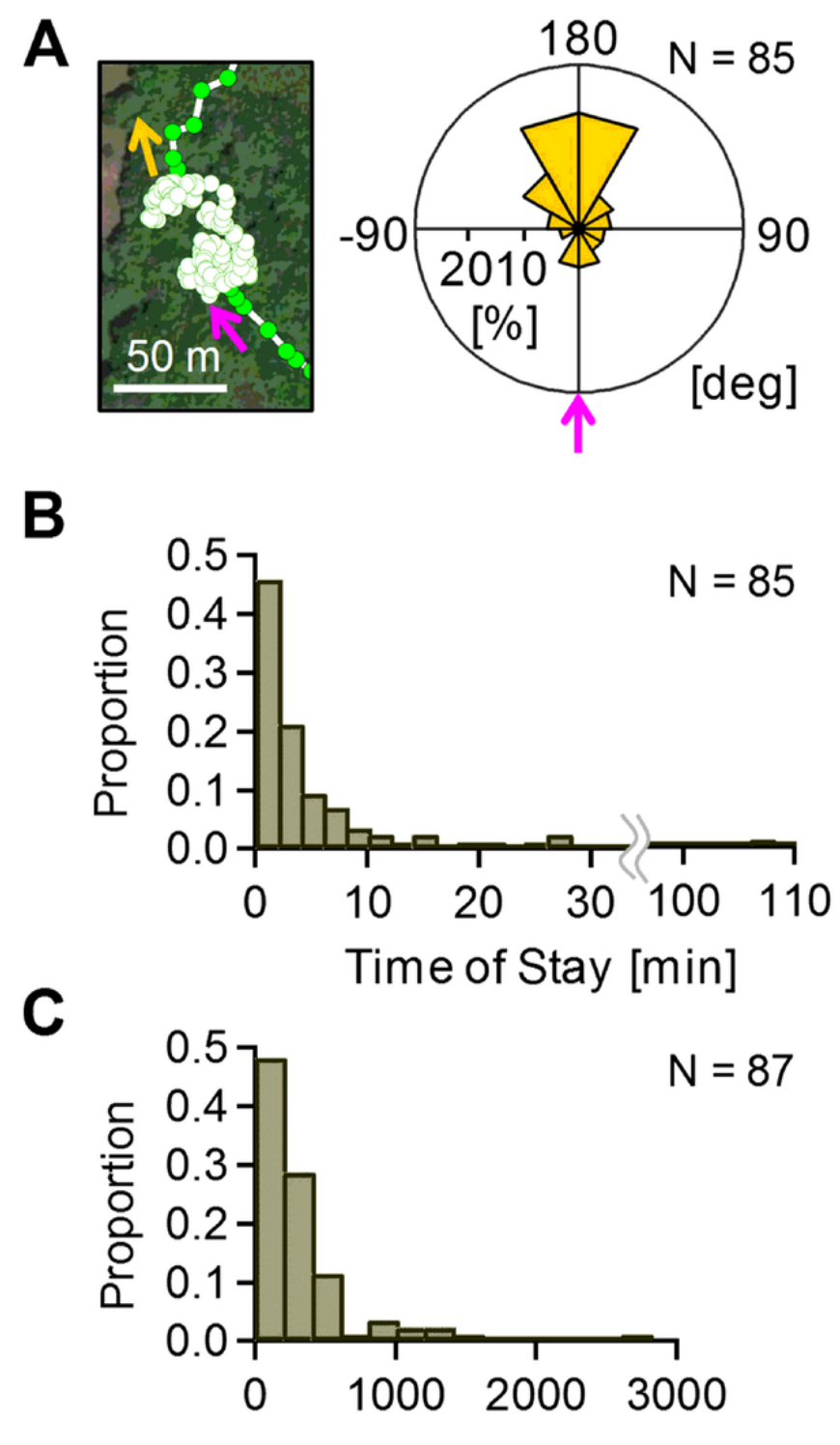

\section{Distance between Stay [m]}

Figure 2

(A) (Left) Example of trajectory pattern around the foraging mode (open circles). Magenta and yellow arrow indicates direction in which bats aimed to fly immediately before entering and after leaving the site of foraging mode, respectively. (Right) Distribution of directions in which bats left the site of foraging mode relative to the direction of entry (magenta direction). (B) Proportional distribution of time bats spent at the site of foraging mode. If the start point of the trajectories of each bat was categorized as foraging-mode, the time of the first stay was not used (the same is true for the last stay). (C) Proportional distribution of distances between two successive stay sites. A geodesic line was used to calculate distances. Note: The designations employed and the presentation of the material on this map do not imply the expression of any opinion whatsoever on the part of Research Square concerning the legal status of any country, territory, city or area or of its authorities, or concerning the delimitation of its frontiers or boundaries. This map has been provided by the authors. 

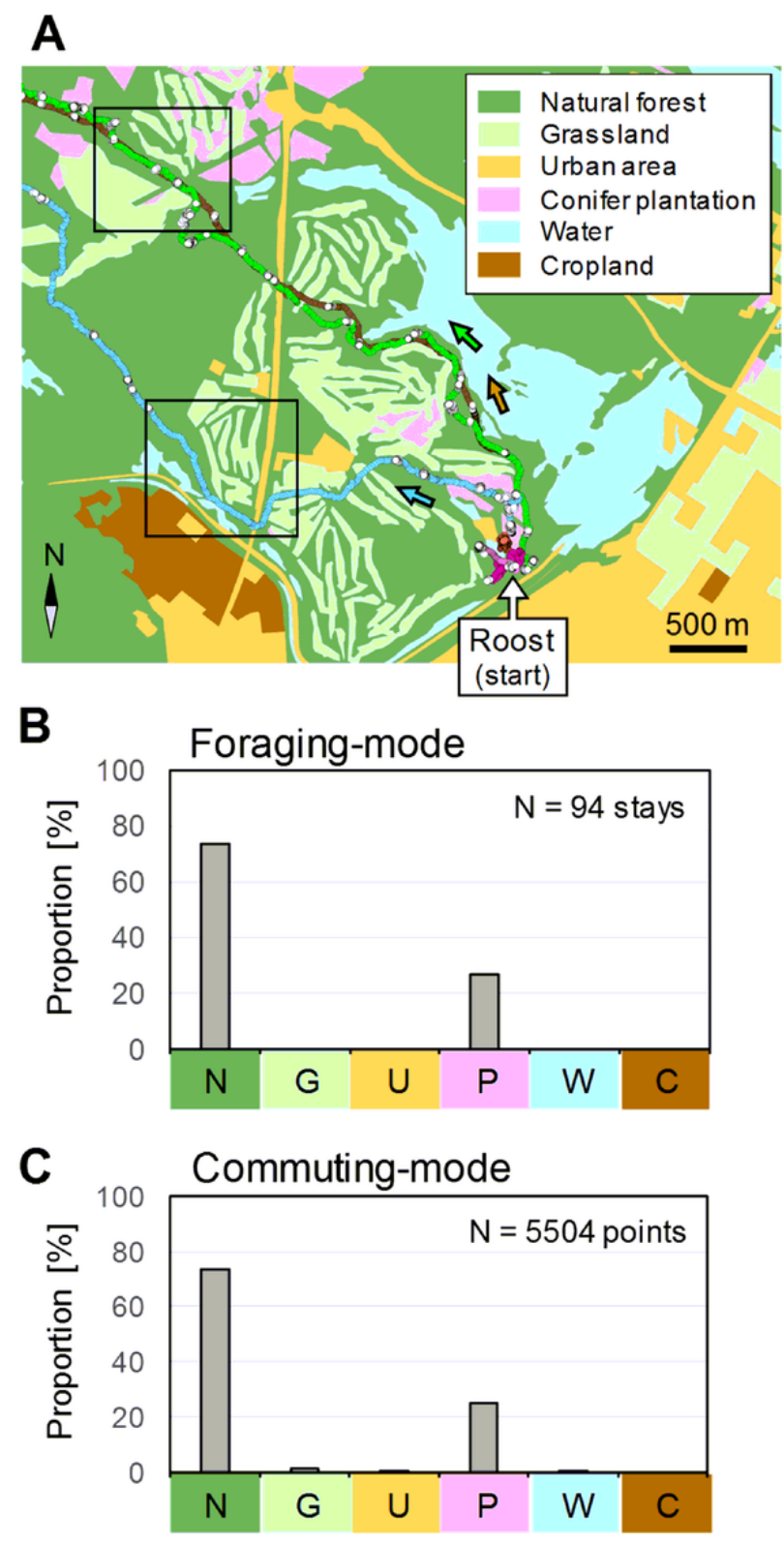

Figure 3

(A) Bat flight path shown on a land-use map of the area around the bat roost. Circles and arrows show paths and directions of bat flights, respectively. White circles indicate locations of foraging-mode behavior. (B, C) Overview of proportions of GPS points associated with different habitat types during foraging (B) and commuting (C). Note: The designations employed and the presentation of the material on this map do not imply the expression of any opinion whatsoever on the part of Research Square concerning the legal status of any country, territory, city or area or of its authorities, or concerning the delimitation of its frontiers or boundaries. This map has been provided by the authors. 

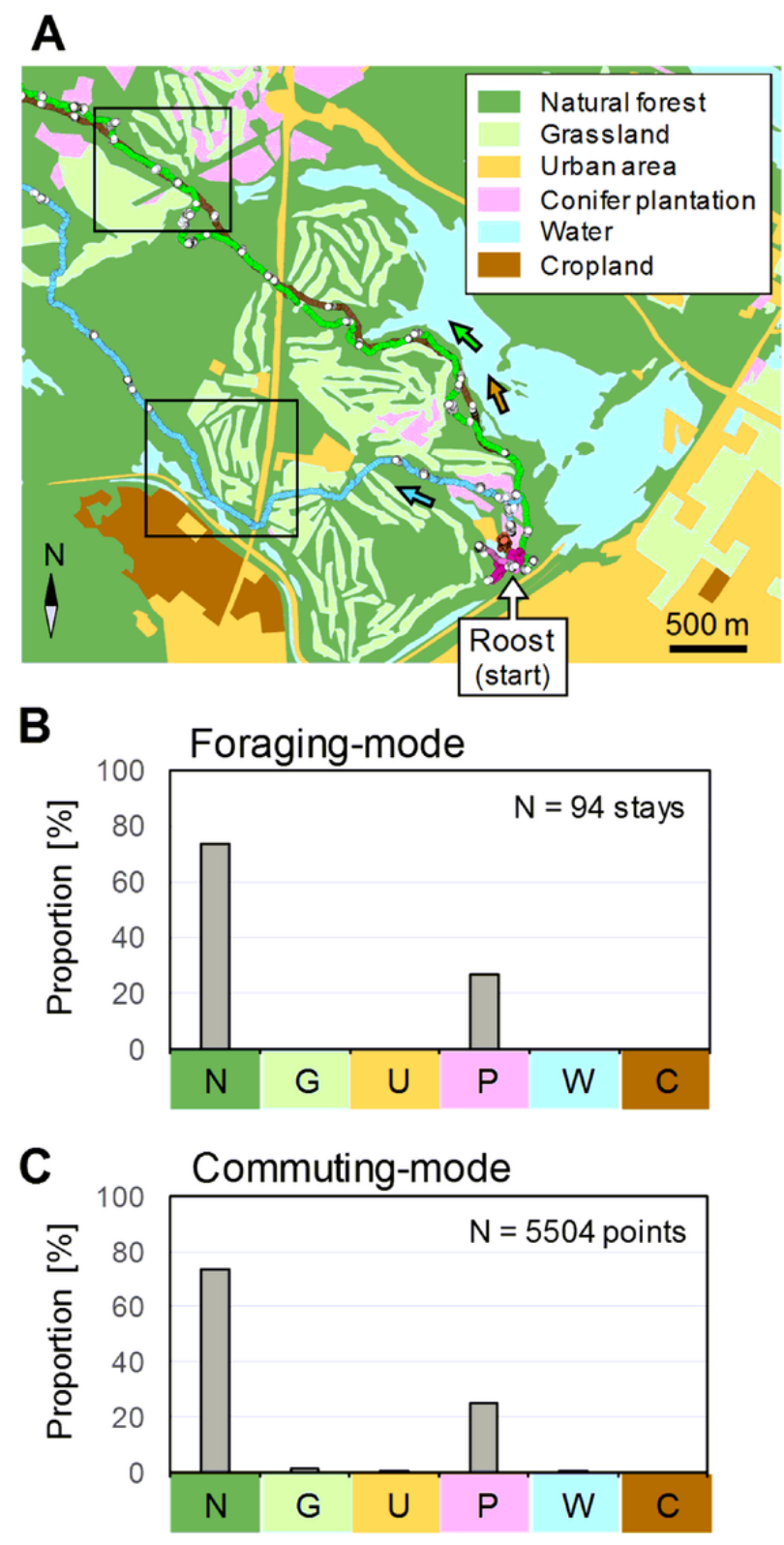

Figure 3

(A) Bat flight path shown on a land-use map of the area around the bat roost. Circles and arrows show paths and directions of bat flights, respectively. White circles indicate locations of foraging-mode behavior. (B, C) Overview of proportions of GPS points associated with different habitat types during foraging (B) and commuting (C). Note: The designations employed and the presentation of the material on this map do not imply the expression of any opinion whatsoever on the part of Research Square concerning the legal status of any country, territory, city or area or of its authorities, or concerning the delimitation of its frontiers or boundaries. This map has been provided by the authors. 

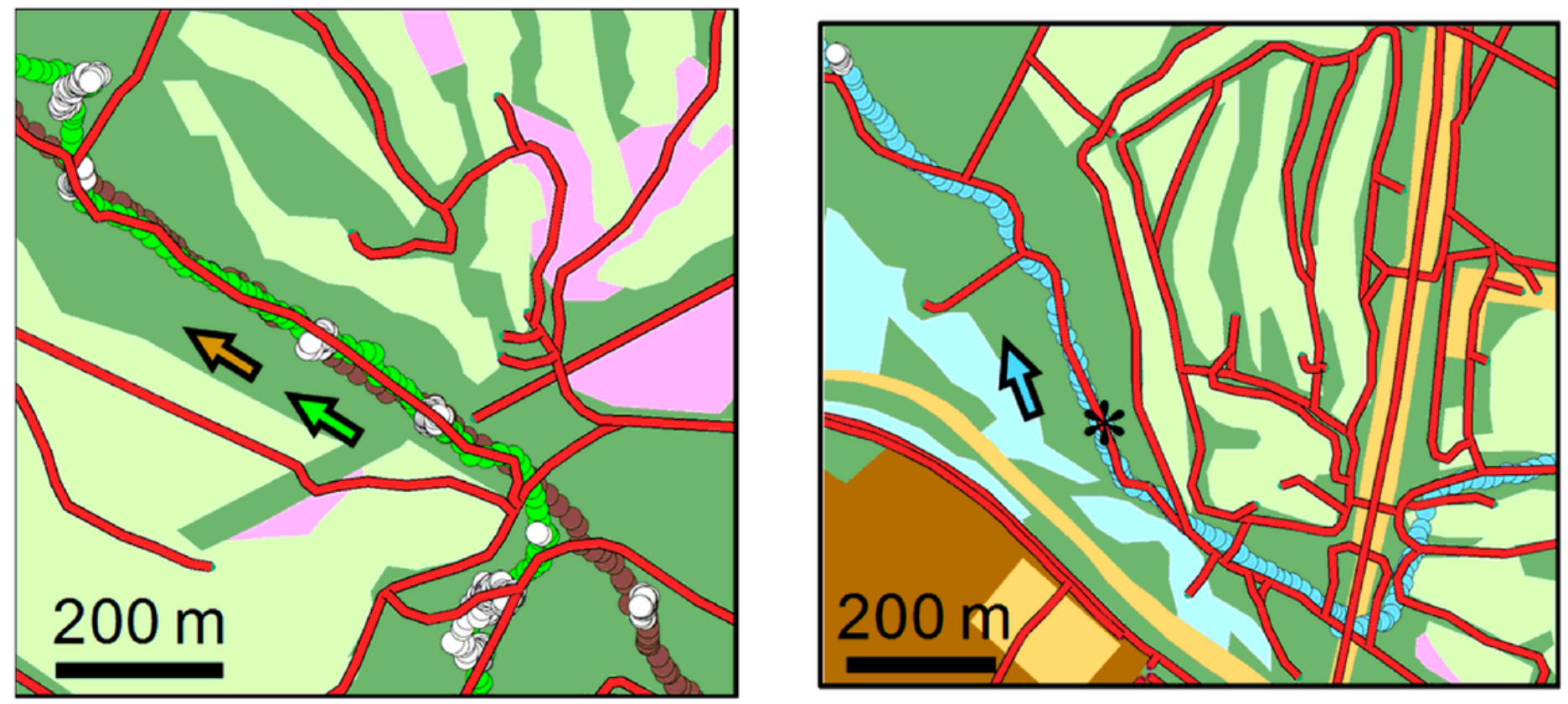

\section{Figure 4}

Magnified image of Figure 3A (squared portions). Red lines indicate roads traced from a map from the Geospatial Information Authority of Japan website. Asterisk in right figure indicates the position from which the photograph (Additional file 1) was taken. Note: The designations employed and the presentation of the material on this map do not imply the expression of any opinion whatsoever on the part of Research Square concerning the legal status of any country, territory, city or area or of its authorities, or concerning the delimitation of its frontiers or boundaries. This map has been provided by the authors.
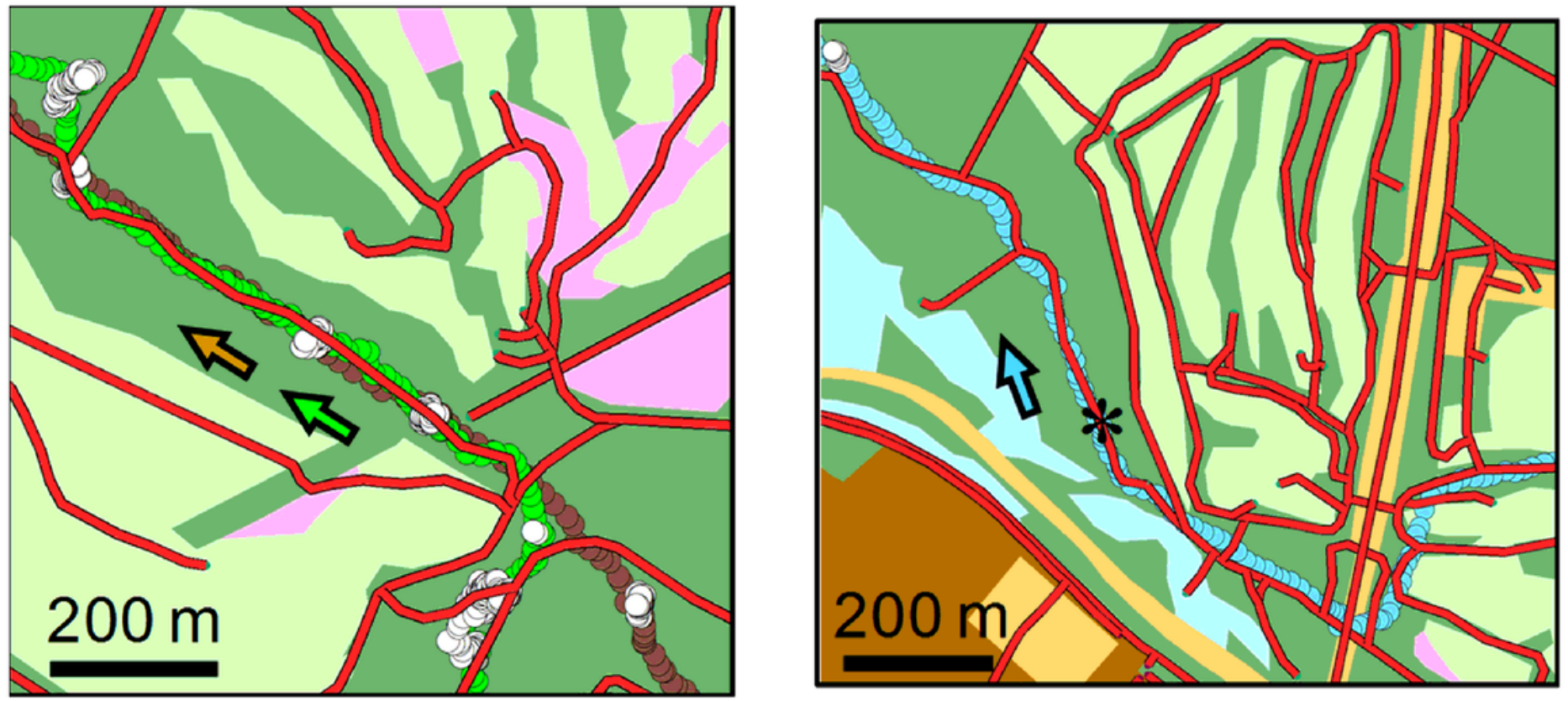

Figure 4

Magnified image of Figure 3A (squared portions). Red lines indicate roads traced from a map from the Geospatial Information Authority of Japan website. Asterisk in right figure indicates the position from which the photograph (Additional file 1) was taken. Note: The designations employed and the presentation of the material on this map do not imply the expression of any opinion 
whatsoever on the part of Research Square concerning the legal status of any country, territory, city or area or of its authorities, or concerning the delimitation of its frontiers or boundaries. This map has been provided by the authors.

\section{Supplementary Files}

This is a list of supplementary files associated with this preprint. Click to download.

- Additionalfile1.jpg

- Additionalfile1.jpg

- Additionalfile2.pdf

- Additionalfile2.pdf

- Additionalfile3.pdf

- Additionalfile3.pdf

- additionalfile4.pdf

- additionalfile4.pdf

- Additionalfile5.pdf

- Additionalfile5.pdf 